\title{
Congenital Ovarian-Fallopian Tube Agenesis Predisposes to Premature Surgical Menopause: A Report of Two Cases
}

Keywords: Ovarian agenesis; Menopause; Infertility; Ovarian torsion

\section{Abstract}

Background: Congenital agenesis of the Fallopian tube and ovary is a rare condition. Although several cases have been published on this condition, none have reported surgical menopause. We present two cases of congenital unilateral tubal and ovarian absence leading to surgic al menopause.

Case presentation: Case 1 underwent laparoscopic surgery for recurrent ovarian torsion and was found to have agenesis of the distal Fallopian tube and ovary. Case 2 underwent laparotomy for an adnexal mass and was found to have unilateral absence of the Fallopian tube and ovary with a contralateral large mucinous cystadenocarcinoma.

Conclusion: Two cases of unilateral ovarian and partial tuba agenesis predisposed the patients to early menopause by requining removal of the contralateral ovary due to recument torsion or ovarian cancer. Upon discovery of congenital absence of an ovary during surgery, an effort should be made to preserve the functionality of the contralateral adnexa and uterus if fertility is desired.

\section{Introduction}

Unilateral absence of a portion of the Fallopian tube with adjacent ovarian agenesis is an uncommon condition. Its incidence has been reported to be 1:11,240 based on a retrospective surgical report from one hospital, although the true incidence in the general population is unknown [1]. Two causes of ovarian agenesis have been proposed previously. Ovarian torsion occurring during fetal life may give rise to necrosis and autoamputation of the tube and ovary [2]. Alternatively, the organs may be absent due to a defect in development of the Mullerian and mesonephric systems [3]. Although several studies report cases of unilateral ovarian absence [1-11], we are unaware of cases in which premature surgical menopause resulted (Table 1). We report two cases of unilateral ovarian absence discovered during surgery of the contralateral ovary that resulted in undesired premature menopause.

\section{Case Presentation}

\section{Case 1}

A 13-year-old nulliparous female presented to our Reproductive Endocrinology office with hot flashes and amenorrhea. Menarche began at age 11. Her history was significant for ovarian torsion occurring twice in the past two years, each requiring laparoscopy by her gynecologist. During the first laparoscopy, the right ovary was detorsed successfully, and a benign luteinized follicular ovarian cyst was removed. It was noted that the short left tube was clubbed with fimbria not identified, and the left ovary appeared to be small and

\section{Journal of}

Andrology \& Gynaecology Maya Barsky*, Ashley M. Beaulieu and Cynthia K.
Sites

Department of Obstetrics \& Gynecology, Division of Reproductive Endocrinology \& Infertility, Baystate Medical Center, Tufts University School of Medicine, USA

\section{*Address for Correspondence}

Maya Barsky, M.D., Department of Obstetrics and Gynecology, Division of Reproductive Endocrinology and Infertility, Baystate Medical Center, Tufts University School of Medicine, 759 Chestnut Street, S1683, Springfield, MA 01199, USA, Tel: +1-413-794-5608; Fax: 413-794-8166; E-mail: maya.barskymd@bhs.org

Submission: 24 February, 2015

Accepted: 01 April, 2015

Published: 04 April, 2015

Reviewed \& Approved by: Dr. Lee Byung Seok, Professor, Department of Obstetrics and Gynecology, Gangnam Severance Hospital, Yonsei University in Seoul, Korea

retroperitoneal. The patient was started on oral contraceptive pills, but two years later, her right lower quadrant pain recurred. Ultrasound and CT scans showed a large pelvic mass with no identification of the left ovary. The uterus and kidneys bilaterally were normal. During the second laparoscopy, the right ovary was found to be necrotic and torsed (Figure 1A) with blood in the pelvis, and a laparoscopic right salpingo-oophorectomy was performed. The left Fallopian tube again appeared blunted with a possible retroperitoneal rudimentary ovary (Figure 1B). After surgery, the patient reported hot flashes and amenorrhea, and was referred to the Reproductive Endocrinology office. Laboratory studies were consistent with menopause, including an FSH of $35 \mathrm{mIU} / \mathrm{ml}$ and an anti-Mullerian hormone level of $<0.3 \mathrm{ng} / \mathrm{ml}$. She was started on vitamin D supplementation and combination estrogen plus progestin patch hormone therapy. She was counselled that she would require donor egg or adoption in the future if she desired children.

\section{Case 2}

A 31-year-old nulliparous woman presented to the gynecology office due to increasing abdominal girth, left upper quadrant pain, and frequent menses. Menarche was at age 11 years, and menses were previously regular. She had no significant medical history or prior gynecological surgeries. A pelvic ultrasound revealed a cystic left adnexal mass, $26 \mathrm{~cm}$ in its largest diameter, and a normal uterus. A subsequent MRI showed multiple septations and solid components within the mass, with a normal uterus and normal kidneys. Tumor markers were drawn and included a CEA of $5.3 \mathrm{ng} / \mathrm{ml}$ and a CA125 of 105 units/ml. Due to concerns about cancer, a laparotomy with left salpingo-oophorectomy, omentectomy, and appendectomy was performed by a gynecologic oncologist. A large left ovarian mass was resected, identified as a mucinous cystadenocarcinoma of low malignant potential (ovarian cancer stage 1A). At surgery, an exploration of the abdomen revealed the absence of a right Fallopian tube and ovary and a normal uterus. No further surgery or chemotherapy was recommended. The patient then reported 
Citation: Barsky M, Beaulieu AM, Sites CK. Congenital Ovarian-Fallopian Tube Agenesis Predisposes to Premature Surgical Menopause: A Report of Two Cases. J Androl Gynaecol. 2015;3(1): 3.

\section{ISSN: 2332-3442}

Table 1: Literature review: Congenital absence of ovary and Fallopian tube.

\begin{tabular}{|c|c|c|c|c|c|c|}
\hline Case & Author (reference) & Tube/ovary status & $\begin{array}{l}\text { Uterine } \\
\text { anomaly }\end{array}$ & Urinary tract anomaly & $\begin{array}{l}\text { Method of } \\
\text { diagnosis }\end{array}$ & $\begin{array}{c}\text { Surgical } \\
\text { menopause } \\
\text { resulted }\end{array}$ \\
\hline 1 & Sivanesaratnam [1] & Absent left tube and ovary & No & $\begin{array}{l}\text { None on intravenous } \\
\text { urogram }\end{array}$ & Laparoscopy & No \\
\hline 2 & Sivanesaratnam [1] & Absent right tube and ovary & No & $\begin{array}{l}\text { None on intravenous } \\
\text { urogram }\end{array}$ & Laparoscopy & No \\
\hline 3 & Uckuyu et al. [2] & Absent left distal tubal segment, streak left ovary & No & $\begin{array}{l}\text { None on excretory } \\
\text { urogram }\end{array}$ & Laparoscopy & No \\
\hline 4 & Uckuyu et al. [2] & Absent right distal tubal segment, normal right ovary & No & $\begin{array}{l}\text { None on renal } \\
\text { ultrasound }\end{array}$ & Laparoscopy & No \\
\hline 5 & Uckuyu et al. [2] & $\begin{array}{l}\text { Absent left ovary, twisted left tube, } 1 \mathrm{~cm} \text { hypoplastic ovarian tissue } \\
\text { in omentum }\end{array}$ & No & $\begin{array}{l}\text { None on renal } \\
\text { ultrasound }\end{array}$ & Laparoscopy & No \\
\hline 6 & Uckuyu et al. [2] & Agensis left ovary, torsion of right ovary & No & $\begin{array}{l}\text { None on renal } \\
\text { ultrasound }\end{array}$ & Laparoscopy & No \\
\hline 7 & Pabuccu et al. [3] & Absent left tube and ovary & No & None on IVP & Laparoscopy & No \\
\hline 9 & Muppala et al. [5] & Absent right ovary, tube, round ligament & No & Right renal agenesis & Laparoscopy & No \\
\hline 10 & Mulayim et al. [6] & Absent left ovary, round ligament, and tube & $\begin{array}{c}\text { Unicornuate } \\
\text { uterus }\end{array}$ & Pelvic kidney & Laparoscopy & No \\
\hline 11 & Mylonas et al. [7] & Absent right tube and ovary & No & None on CT & Laparoscopy & No \\
\hline 12 & Mylonas et al. [7] & Absent right tube and ovary & No & $\begin{array}{l}\text { None on renal } \\
\text { ultrasound }\end{array}$ & Laparoscopy & No \\
\hline 13 & Mylonas et al. [7] & Right adnexal aplasia, left ovarian agenesis, adherent left tube & No & None mentioned & Laparoscopy & No \\
\hline 14 & Sirisena [8] & Absent left ovary, only $2 \mathrm{~cm}$ of left tube from cornual end & No & None on IVP & $\begin{array}{l}\text { Exploratory } \\
\text { laparotomy }\end{array}$ & No \\
\hline 15 & Rapisarda et al. [9] & Absent left ovary, $1 \mathrm{~cm}$ left tubal residue & No & None mentioned & Laparoscopy & No \\
\hline 16 & Chen et al. [10] & Absent left ovary, distal $2 \mathrm{~cm}$ left tubal remnant & No & None on MRI & Laparoscopy & No \\
\hline 17 & Eustace [11] & Absent right ovary, $1 \mathrm{~cm}$ blind ended left and right tube & No & $\begin{array}{l}\text { None on intravenous } \\
\text { urogram }\end{array}$ & Laparoscopy & No \\
\hline 18 & Eustace [11] & Absent right ovary, $1 \mathrm{~cm}$ blind ending tube from cornual region & No & None mentioned & Laparoscopy & No \\
\hline
\end{tabular}

hot flashes and amenorrhea, and was referred to the Reproductive Endocrinology office. A transvaginal ultrasound revealed a normal uterus, an absent left ovary, and a right ovary that could not be visualized. Further laboratory evaluation confirmed menopausal status including an FSH of $82.7 \mathrm{mIU} / \mathrm{ml}$ and an anti-Mullerian hormone level of $0.3 \mathrm{ng} / \mathrm{ml}$. The patient was started on oral estrogen and progestin therapy and vitamin $\mathrm{D}$ supplementation. She was

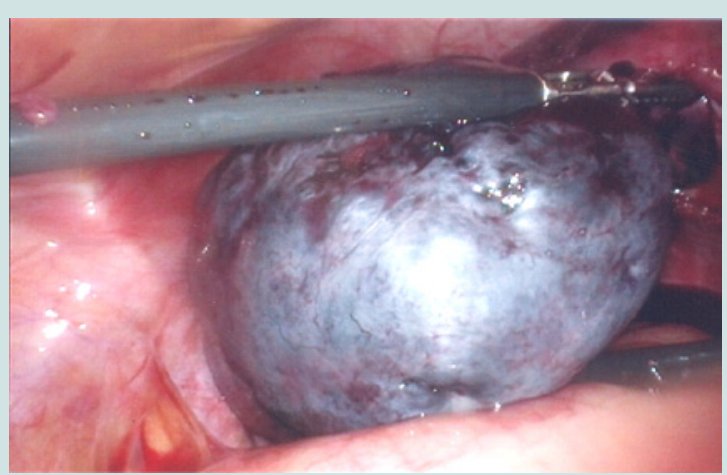

Figure 1a: In case 1, the right ovary was found to be necrotic and torsed during the second laparoscopy.

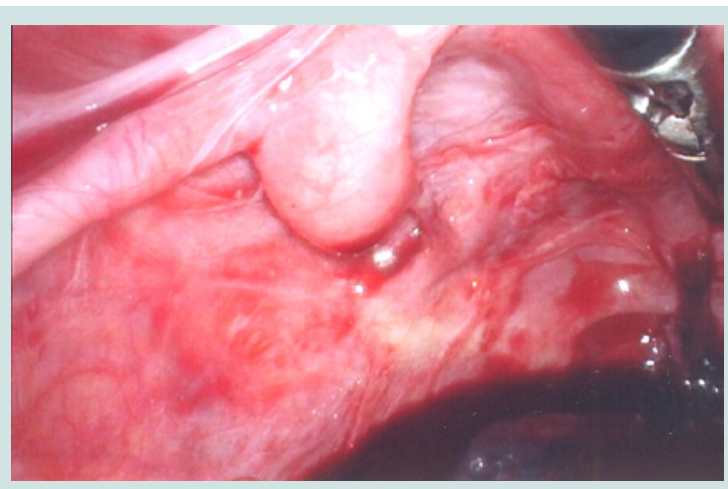

Figure 1b: The left Fallopian tube appeared blunted with a possible retroperitoneal rudimentary ovary, and blood was noted in the pelvis.

interested in fertility, and was given information about the donor egg program.

\section{Discussion}

Congenital unilateral agenesis of the ovary and Fallopian tube is a relatively unknown and unappreciated condition. Two possible etiologies of the condition have been reported: adnexal torsion and 
Citation: Barsky M, Beaulieu AM, Sites CK. Congenital Ovarian-Fallopian Tube Agenesis Predisposes to Premature Surgical Menopause: A Report of Two Cases. J Androl Gynaecol. 2015;3(1): 3.

failure of embryologic development of the Mullerian and mesonephric system $[2,3]$.

Adnexal torsion of a long ovarian pedicle or mesosalpinx can lead to avascular necrosis, separation of tissue, and resorption, which can explain unilateral absence of the ovary. Torsion is associated with severe abdominal pain in adults, but may go unnoticed in childhood or fetal life. Fetal ovarian cysts have been confirmed in two small studies $[13,14]$. In these reports, $9-35 \%$ had prenatal resolution of the cysts. However, $10-29 \%$ of infants had confirmed ovarian torsion. The incidence of torsion did not differ between complex and simple cysts, or between cyst sizes less than or greater than $40 \mathrm{~mm}$ diameter [14]. Given that ovarian torsion can occur in utero, the ovarian torsion hypothesis as a cause of ovarian absence is possible especially if remnants of the torsed fetal tissue are found during subsequent surgery. Uckuyu et al. described three such cases [2]. Furthermore, two additional cases have been reported in which ovarian masses were found in other intra-abdominal structures, also suggesting adnexal torsion as the etiology $[12,15]$. Neither of our patients had a known history of ovarian cysts during fetal life or early childhood, yet both had cysts during adolescence or early adulthood. We speculate that either or both of our patients had unnoticed cysts in the past that caused ovarian torsion as a mechanism for their ovarian and tubal absence.

Unilateral agenesis of the ovary and Fallopian tube may also be explained by a defect localized in the genital ridge caudal to the Mullerian duct or a defect in the development of the entire Mullerian system [3]. Such a hypothesis was supported by findings of other Mullerian anomalies during the evaluation of patients with ovarian agenesis $[4,6]$. In our cases, both patients had CT scans during their care showing a normal uterus, kidneys, and collecting system, suggesting that Mullerian and mesonephric duct dysgenesis were not the cause of their unilateral ovarian and tubal absence.

Both of our cases resulted in undesired surgical menopause. The first case experienced torsion twice during puberty. During the first laparoscopy, a retroperitoneal ovarian remnant and proximal tubal segment were identified. It is possible that an oophoropexy could have been performed at this time, and thus prevented the subsequent torsion, necrosis, and surgical menopause. This case highlights the importance of considering oophoropexy to prevent recurrence and thus preserve fertility if the contralateral ovary is not clearly present or if there is an elongated utero-ovarian ligament. The procedure can be performed laparoscopically with plication of the uteroovarian ligament, fixation of the ovary to the pelvic side wall or to the uterosacral ligament all using nonabsorbable suture [16].

Our second case had no history of ovarian torsion during childhood or adulthood, and was found to have congenital ovarian absence after undergoing laparotomy. A large mucinous cystadenoma of low malignant potential was identified. Childhood ovarian cysts include a small proportion of mucinous tumors [17], most of which are borderline or of low malignant potential $[17,18]$. While only $10 \%$ of mucinous adenocarcinomas are bilateral [19], it is possible that she may have had an earlier mucinous tumor that resulted in torsion.

Unilateral absence of the adnexa may reduce the probability of becoming pregnant, especially if the etiology is likely due to an ovarian cyst and torsion. Both cases presented with unilateral ovarian agenesis that was discovered during surgery. Both resulted in removal of the contralateral ovary due to an ovarian cyst, leading to unwanted surgical menopause. Fortunately, the uterus was conserved for these patients, leaving them the option of receiving donor eggs for pregnancy.

\section{References}

1. Sivanesaratnam V (1986) Unexplained unilateral absence of ovary and fallopian tube. Eur J Obstet Gynecol Reprod Med 22: 103-105.

2. Uckuyu A, Ozcimen EE, Sevinc Ciftci FC (2009) Unilateral congenital ovarian and partial tubal absence: report of four cases with review of literature. Fertil Steril 91: 936.

3. Pabuccu E, Kahraman K, Taskn S, Atabekoglu C (2011) Unilateral absence of fallopian tube and ovary in an infertile patient. Fertil Steril 96: e55-e57.

4. Suh BY, Kalan MJ (2008) Septate uterus with left fallopian tube hypoplasia and ipsilateral ovarian agenesis. J Assist Reprod Genet 25: 567-569.

5. Muppala H, Sengupta S, Martin JE (2008) Unilateral absence of tube and ovary with renal agenesis and associated pyloric stenosis: communication. Eur J Obstet Gynecol Reprod Biol 137: 123.

6. Mulayım B, Demirbasoglu S, Oral O (2003) Unicornuate uterus and unilatera ovarian agenesis associated with pelvic kidney. Surg Endosc 17: 161.

7. Mylonas I, Hansch S, Markmann S, Bolz M, Friese K (2003) Unilateral ovarian agenesis: report of three cases and review of literature. Arch Gynecol Obstet 268: 57-60.

8. Sirisena LA (1978) Unexplained absence of an ovary and uterine tube. Postgrad Med J 54: 423-424.

9. Rapisarda G, Pappalardo EM, Arancio A, La Greca M (2009) Unilateral ovarian and fallopian tube agenesis. Arch Gynecol Obstet 280: 849-850.

10. Chen B, Yang C, Sahebally Z, Jin H (2014) Unilateral ovarian and fallopian tube agenesis in an infertile patient with a normal uterus. Exp Ther Med 8: 831-835.

11. Eustace DL (1992) Congenital absence of fallopian tube and ovary. Eur J Obstet Gynecol Reprod Biol 46: 157-159.

12. Sebastian JA, Baker RL, Cowdray D (1972) Asymptomatic infarction of ovary and distal uterine tube. Obstet Gynecol 41: 531-532.

13. Turgal M, Ozyuncu O, Yazicioglu A (2013) Outcome of sonographically suspected fetal ovarian cysts. J Matern Fetal Neonatal Med 26: 1728-1732.

14. Nakamura M, Ishii K, Murata M, Sashara J, Mitsuda N (2015) Postnatal outcome in cases of prenatally diagnosed fetal ovarian cysts under conservative prenatal management. Fetal Diagn Ther 37: 129-134.

15. Silva PD, Glasser KE, Virata R (1995) Spontaneously acquired, unilateral absence of the adnexa. A case report. J Reprod Med 40: 63-64.

16. Fuchs N, Smorgick N, Tovbin Y, Ben Ami I, Maymon R, et al. (2010) Oophoropexy to prevent adnexal torsion: how, when, and for whom? J Minim Invasive Gynecol 17: 205-208.

17. Hazard FK, Longacre TA (2013) Ovarian surface epithelial neoplasms in the pediatric population: incidence, histologic subtype, and natural history. Am J Surg Pathol 37: 548-553.

18. Brown MF, Hebra A, McGeehin K, Ross AJ 3rd (1993) Ovarian masses in children: a review of 91 cases of malignant and benign masses. J Pediatr Surg 28: 930-933.

19. Seidman JD, Ronnett BM, Kurman RJ (2002) Pathology of borderline (low malignant potential) ovarian tumours. Best Pract Res Clin Obstet Gynaecol 16: 499-512.

Copyright: (c) 2015 Barsky M, et al. This is an open access article distributed under the Creative Commons Attribution License, which permits unrestricter permits unrestricted use, distribution, and reproduction in any medium, provided the original work is properly cited. 